\section{Construindo a (Tríplice) Fronteira}

Verónica Giménez BÉLIVEAU e Silvia MONTENEGRO. La triple frontera: globalización y construcción social del espacio. Buenos Aires, Miño \& Dávila, 2006. 256 páginas.

\section{Arthur Bernardes do Amaral}

Fonte de ampla polêmica na mídia internacional e objeto de constantes disputas nos meios governamentais, a chamada Tríplice Fronteira ainda é um objeto pouco explorado por pesquisadores das diversas áreas das ciências sociais. Nos últimos anos, contudo, a região de intersecção das fronteiras de Brasil, Argentina e Paraguai tem angariado maior atenção da academia, sobretudo em virtude da alegação, oriunda de determinados setores do governo norte-americano, de que a área seria refúgio para agentes do terrorismo internacional ou fonte de financiamento das atividades desses atores em outras partes do mundo.

No âmbito desse novo interesse acadêmico pela temática, tem-se multiplicado a produção que trata da região em seus mais variados aspectos. Muitas dessas novas contribuições, contudo, carecem de maior sofisticação analítica. Particularmente no campo dos estudos de segurança internacional - em certo sentido, o carro-chefe da nova onda de produção no pós-11 de Setembro - essa subteorização se faz evidente. Todavia, há outras abordagens no âmbito das ciências sociais que nos fazem crer na viabilidade de uma pesquisa empiricamente rica e teoricamente informada. Um dos exemplos que poderíamos citar nesse sentido é a contribuição das cientistas sociais Verónica Giménez Béliveau e Silvia Montenegro em La triple frontera: globalización y construcción social del espacio.

Nesse livro editado em 2006, as autoras nos apresentam a Tríplice Fronteira como uma entidade imaginada, um espaço socialmente construído por meio das representações dos variados atores que a ele se referem e lhe conferem atributos. Esse argumento inicial - que, efetivamente, é a principal tese das autoras - demonstra a especificidade da abordagem de Béliveau e Montenegro: no argumentar das autoras, a Tríplice Fronteira não é reifi- cada, mas tida como um produto essencialmente social. Não se faz necessária, nesse sentido, a existência de um marco físico que delimite e encerre esse espaço. Sendo uma construção social, e não um dado da natureza, a Tríplice Fronteira é um espaço essencialmente fluido, multiforme e portador de atributos muitas vezes contraditórios.

Essas contradições, por sua vez, expressam a disputa entre as diferentes representações atribuídas à Tríplice Fronteira. E são essas tensões que orientam a discussão das autoras e organizam a divisão do livro em duas partes principais. A primeira parte se dedica à análise dos discursos relativos à Tríplice Fronteira em diferentes meios de comunicação escrita. Já a segunda tem como foco a especificidade dos discursos dos atores locais, isto é, aqueles que residem na fronteira.

Nos três capítulos contidos nessa primeira parte da obra, Béliveau e Montenegro nos oferecem um amplo panorama das representações contidas (1) na mídia internacional, (2) na mídia Argentina e (3) na mídia "alternativa" (los altermedios). É exatamente nessas três seções que a análise das autoras se mostra de particular utilidade para pesquisadores da área de Relações Internacionais, mais especificamente para aqueles interessados em exemplos de como operacionalizar empiricamente aportes teóricos alternativos ao mainstream racionalista que ainda domina a disciplina.

A análise de variadas fontes internacionais CNN, The Washington Post, The New York Times, The Washington Times, BBC, Military Review e relatórios governamentais norte-americanos - permite às autoras traçar com competência a gênese das representações sobre a Tríplice Fronteira que informam e pretendem justificar as ações de atores externos à região. Embora se restrinjam a esse âmbito, não enunciando de forma explícita a relação entre discurso e constituição da ação internacional dos atores externos à Tríplice Fronteira, Béliveau e Montenegro fornecem uma útil sistematização dessas retóricas. Fica então a nosso cargo inferir essas ações e entender, por fim, quais mecanismos discursivos possibilitaram, em um primeiro momento, a constituição da área (1) como foco de ameaça à segurança dos Estados (Unidos) e (2) como requerente de maiores controles do Estado soberano. 
A análise da mídia argentina - Clarín e $\mathrm{La} N a$ ción - que se segue é exaustiva e um dos trunfos do livro. As trajetórias das pautas, temas e discursos que se fazem presentes nas notícias dos dois principais jornais argentinos são diversos o bastante para incluir representações tão contraditórias sobre a Tríplice Fronteira como um "ninho de espiões"; uma área sem lei e controles estatais; um local de células adormecidas (células dormidas) de grupos como o Hizballah, al-Qaeda e Hamas; um objeto de cobiça internacional por seus recursos aqüíferos etc.

Os interesses internacionais em controlar os recursos naturais e econômicos existentes na região tornam-se o eixo central de contra-argumentação dos chamados altermedios, a mídia "alternativa" ou "independente". Há a noção de uma ameaça imperialista que ronda a região. A invasão do Iraque em 2003 dá força à idéia de que uma potência estrangeira seria capaz de "fabricar" evidências com o intuito de justificar o controle sobre uma área rica em recursos naturais. Dentro dessa lógica "antiimperialista", da mesma forma que os Estados Unidos fizeram uso de evidências falsas para justificar a invasão do Iraque e controlar seu petróleo, as acusações sobre a existência de terrorismo na Tríplice Fronteira poderiam servir para justificar a intervenção norte-americana na área em busca dos recursos hídricos do Aqüífero Guarani.

A segunda parte do livro é dedicada à análise dos atores locais e tem um viés marcadamente antropológico. As autoras buscam desvendar as formas e os expedientes utilizados pelos diferentes atores religiosos para produção do espaço em que habitam na fronteira. A clara articulação entre as identidades locais dos habitantes das cidades fronteiriças e as identidades nacionais dos seus respectivos países é particularmente interessante. A narrativa dos atores locais sobre os atributos de cada uma das três cidades está, nesse sentido, mais ligada aos seus respectivos mitos nacionais - por exemplo, da diversidade e tolerância étnico-cultural brasileira - do que propriamente ao caráter particular da Tríplice Fronteira enquanto região transfronteiriça de contato intenso entre três nacionalidades. Em certo sentido, mesmo em uma região onde as fronteiras são cruzadas cotidianamente, "O Nacional" sustenta fronteiras sociológicas que informam as representações que os atores têm da própria identidade e da alteridade com a qual interagem.

Levando em conta que os problemas que os atores locais atribuem à região também fazem parte da construção de representações sobre o espaço, Béliveau e Montenegro analisam o modo como esses agentes locais buscam retirar a particularidade da área, inserindo a Tríplice Fronteira em um conjunto de dinâmicas mais gerais, que a associa a problemas presentes em outras partes do mundo (Lógica da Universalização), na América Latina (Lógica da Latinoamericanização) ou em outras áreas de fronteira pelo globo (Lógica da Fronteirização). Os variados fluxos transfronteiriços que têm lugar na área são então tratados pelas autoras para evidenciar as assimetrias intrínsecas a essas circulações e, assim, operar uma contraposição entre essa realidade inerentemente complexa e a representação homogênea apresentada pela mídia internacional. $\mathrm{O}$ foco na religião permite a Béliveau e Montenegro compreenderem os variados modos por meio dos quais essa componente pôde constituir espacialidades diversas, tendo na diferença entre católicos - para quem os espaços estão compartimentados em Estados nacionais - e neopentecostais - que não reconhecem fronteiras para seu espaço de pregação - o mais claro exemplo dessas formas díspares de apropriação do mesmo espaço.

Por fim, Damián Setton - também sociólogo, que colaborou com o trabalho de campo e a redação do último capítulo do livro - se junta a Béliveau e Montenegro para nos falar das "constelações ideológicas" construídas em torno da região transfronteiriça, sobretudo a partir da narrativa dos participantes do Fórum Social da Tríplice Fronteira (FSTF). O capítulo, de certa forma, repete os argumentos e conclusões já apresentadas nas seções anteriores, tendo sua originalidade contida basicamente no trato das narrativas dos atores operantes no âmbito do Fórum Social e em mídias correlatas.

Como as próprias autoras admitem, o livro é fruto da convergência de experiências de trabalho diversas. Esse caráter fica evidente na organização do livro em duas partes distintas, dando ao leitor a impressão de ter havido uma clara divisão e fragmentação do trabalho entre as autoras. Essa divisão, mesmo que de forma tênue, se faz sentir na 
passagem da primeira à segunda parte do livro transição que, mesmo operada de forma competente pelas autoras, faz transparecer uma sutil descontinuidade. Nesse sentido, poderíamos dizer que o livro é composto por duas obras independentes, que abordam o mesmo objeto, a partir de uma mesma disciplina, com as mesmas premissas epistemológicas, mas com focos e olhares diversos. Nesse particular reside tanto a peculiaridade quanto a riqueza do texto de Béliveau e Montenegro.

O comentário quanto à divisão de responsabilidades, admito, é potencialmente equivocado ou mesmo injusto se considerarmos a sempre presente articulação entre as diferentes seções do livro e a recorrente menção a outros capítulos. No entanto, é difícil não imaginar essa (absolutamente legítima) opção de trabalho, ainda mais ao observar o capítulo que compartilham com Setton. A repetição (talvez desnecessária) de muitos dos argumentos e conclusões já expressos nos capítulos precedentes e a inserção um tanto repentina da noção de "constelações ideológicas" no último capítulo soam artificiais.

Essas breves críticas, no entanto, não diminuem de forma alguma a importância da contribuição de Béliveau e Montenegro. La triple frontera apresentase como uma muito bem-vinda empreitada no sentido de demonstrar a necessidade de uma maior teorização sobre essa controversa e disputada região. $\mathrm{O}$ material empírico coletado, trabalhado e sistematizado - sejam as muitas notícias da mídia ou as inúmeras entrevistas - é de grande valor para quaisquer interessados pela temática da Tríplice Fronteira. As apresentações introdutórias da história, demografia, geografia e economia da região são de grade utilidade para a contextualização dos problemas e questões que hoje tem a Tríplice Fronteira como seu palco.

A obra, poderíamos dizer, reflete a particularidade de seu objeto. Assim como a própria Tríplice Fronteira, o livro de Béliveau e Montenegro é rico, diverso, múltiplo e pode ser observado a partir de pontos de vista bastante distintos. Esse caráter plural e, ao mesmo tempo, coerente faz do texto uma das mais substanciais contribuições disponíveis até o presente momento sobre a temática da Tríplice Fronteira - tanto em relação à qualidade analítica e à densidade teórica, quanto no que se refere à abran- gência dos temas e à extensão do estudo. Às disciplinas de Relações Internacionais e da Antropologia cabe olhá-lo como uma contribuição ao estudo das fronteiras em tempos de globalização, das diferentes representações que se atribui à alteridade $\mathrm{e}$ do sentido da identidade (nacional, religiosa etc.) em uma área onde representações sobre o espaço estão em constante disputa.

Da mesma forma que duas pontes unem três territórios nacionais na região fronteiriça e constituem a Tríplice Fronteira como uma entidade socioespacial tão nova quanto original, o livro de Béliveau e Montenegro pode nos servir como um primeiro elo, um ponto de contato inicial entre duas disciplinas que se mantêm separadas por fronteiras em certo sentido arbitrárias e injustificáveis. Recomendo a leitura do texto na esperança de que, ao compreender o modo como fronteiras são socialmente construídas, possamos transgredir determinadas barreiras disciplinares ainda hoje consagradas (sic) e caminhar no sentido de uma aproximação - incipiente, mas também auspiciosa e necessária - entre os campos da antropologia e das relações internacionais.

\section{ARTHUR BERNARDES DO AMARAL é mestre em Relações Internacionais pelo IRI/PUC-RJ. \\ E-mail: arthur.bernardes@gmail.com.}

